\title{
Efficiency of Mass Selection on Improving Characteristics of Native Radish (Raphanus sativus L.)
}

\author{
Abd-Allah, S. A. M. and Moussa, S. A. M. ${ }^{1}$
}

\begin{abstract}
This investigation was carried out at Sabahia Horticultural Research Station, Alexandria, during the winter seasons of 2007 till 2010. The genetic materials used in this study were three ecotypes of white balady radish; which were collected from Alexandria, Kafr El-Sheikh and Sohag governorates; to study the efficiency of two cycles of mass selection on the general behavior of some of their important characters. Moreover, some important genetic parameters were calculated for the studied characters; as well as the genotypic correlation coefficients among the studied characters; which would be helpful to plan an appropriate selection program.

Wide differences were noticed among and within base populations of the used three balady ecotypes of white radish in most of the studied characters. The coefficients of variation values were higher than $25 \%$ in base populations of the three ecotypes for most characters. Mass selection was found to be effective on enhancing the studied character of the three ecotypes of white balady radish. Furthermore, mass selection method appeared also efficient in reducing coefficients of variation and the detected ranges of most of the characters became narrower. Mean squares of genotypes were found highly significant, only, for the three characters number of leaves, leaf shape and hairiness. The genotype $\times$ year component of variance did not reach the significance level in all studied traits. The insignificance of this component indicated that the selected genotypes successes to posses the same general performance in all years of the test. The partitioning of the estimated variances into its their various components revealed that a large portion of variances of most studied traits of used radish ecotypes would be attributed differences in their genotypes. The estimated broad sense heritability values of the various studied characters reflected generally high estimates (> $80 \%$ ) in most studied traits. Concerning genotypic correlation coefficients among the studied traits of the three radish genotypes, it was found that root weight was positively correlated with all other studied characters, except root shape index. Meanwhile, foliage weight was positively correlated with foliage length, number of leaves and root weight.
\end{abstract}

Key words: Radish, Raphanus sativus L., Mass selection, broad-sense heritability, correlation coefficient.

\section{INTRODUCTION}

Radish (Raphanus sativus L.; $2 n=18$ ) is a popular member of the cruciferae crops, mustard family. It is a cool season annual crop. The white type of radish is one of the popular winter vegetable salad crops in Egypt. Before the building of pyramids, in the days of the pharaohs, the radish was extensively cultivated in ancient Egypt (Schultheis, 1993).

Since, there is no formal Egyptian cv. of white radish; there is a consistent need to get a suitable Egyptian local cultivar of radish, which can be achieves effectively by adapting proper breeding techniques, depending on recognition of the magnitude and nature of genotypic and non-genotypic variations in various plant characters (Wahba et al., 1998). Schultheis (1993) revealed that; to be mild, tender and attractive; the radish plants must grow rapidly. Slow or checked growth results in tough, woody, pithy and pungent roots.

The objectives of the present investigation were to study the efficiency of two cycles of mass selection on the general behavior of some important characters of three local ecotypes of radish. Moreover, some important genetic parameters were calculated for the various studied characters. The genotypic correlation coefficients among the studied characters, which would be helpful to plan an appropriate selection program, were also calculated.

\section{MATERIALS AND METHODS}

This investigation was carried out at Sabahia Horticultural Research Station, Alexandria, during the winter seasons of 2007 till 2010. The used genetic materials were three ecotypes of balady white radish; collected from Alexandria, Kafr El-Sheikh and Sohag governorates.

On the first week of October 2007, seeds of each genotype of radish were sown in 20 rows, $4 \mathrm{~m}$ long and $5 \mathrm{~cm}$ apart. Every two rows were considered as a subplot. After 45 days from sowing, plants were picked up (harvested) with roots. The studied characters were measured on an individual plant basis, and used to calculate means, ranges, and coefficient of variations (C.V.\%). Selection was made according to the criteria; more number of leaves, heavier leaves and roots weights, longer leaves and roots, complete leaves and less hairiness roots. The selected roots were replanted for obtaining seeds of the first selection cycle $(\mathrm{C} 1)$ to grow the following planting cycle. In 2008 winter season, selected seeds of $\mathrm{C} 1$ were sown, the same as in

${ }^{1}$ Horticultural Research Institute, A.R.C., Egypt

Received June26, 2011, Accepted September25, 2011 
the first season, and the plants were subjected to the same agricultural practices. Selection was practiced as done in the first cycle to obtain seeds of the second cycle of mass selection (C2) and, then the harvested seeds were stored. On the first week of October 2009 and 2010, the seeds of base populations (of each ecotype) and those of the selected plants of cycle 1 and cycle 2 were sown in evaluating replicated trials, using a randomized complete blocks design, with three replications. The seeds of each entry were drilled 0.5 to $1.0 \mathrm{~cm}$ deep, in 5 rows, $25 \mathrm{~cm}$ apart and $4 \mathrm{~m}$ long. The plants were thinned out to only one plant each $5 \mathrm{~cm}$. All the agricultural practices were followed according to common recommendations for commercial production to obtain the best growing plants. The plants were harvested after 45 days from sowing.

\section{Recorded data:}

The following characters were recorded on individual plants in each entry.

Foliage characteristics; i.e., foliage length $(\mathrm{cm})$, foliage weight $(\mathrm{g})$, number of leaves/plant, and leaf shape (were scored from 1 to 10 ; whereas, 1 means a segmented leaf blade and 10 means a complete leaf blade).

Root characteristics; i.e., Root length (cm), Hairiness (were scored from 1 to 10; whereas, 1 denotes a hairy root; while, 10 refers to a smooth root), root diameter $(\mathrm{cm})$, root weight $(\mathrm{g})$, and root shape index, which calculated according to Thompson (1969) as follows:

Root shape index $=\frac{\text { Root weight }}{\text { Root diameter } \times \text { Root length } \times \pi}$

Where, $\pi$ is a mathematical constant, approximately, equals to 3.14159 . Root shape index is conical if the value was between $1.00-0.33$ cylindrical if it was $>1.00$

\section{Statistical procedures:}

Data of the studied characters were statistically analyzed, using a combined analysis of variance for the two evaluated seasons, according to Herbert et al. (1955) and as illustrated in Table (1). The differences among the various means were tested, using Duncan's multiple range test (L.S.R.).

Table 1. The combined analyses of variance

\begin{tabular}{lllll}
\hline S.O.V. & D.F. & S.S. & M.S. & E.M.S. \\
\hline Reps./y & $\mathrm{y}(\mathrm{r}-1)=4$ & S.S.r $/ \mathrm{y}$ & S.S.r/y/ $\mathrm{y}(\mathrm{r}-1)$ & \\
\hline Years $(\mathbf{Y})$ & $(\mathrm{y}-1)=1$ & S.S.y & S.S.y/ $(\mathrm{y}-1)$ & $\sigma_{\mathrm{e}}^{2}+\mathrm{r} \sigma_{\mathrm{gy}}^{2}+\mathrm{gr} \sigma_{\mathrm{y}}^{2}$ \\
\hline Genotypes $(\mathbf{G})$ & $(\mathrm{g}-1)=2$ & S.S.g & S.S.g/ $(\mathrm{g}-1)$ & $\sigma_{\mathrm{e}}^{2}+\mathrm{r} \sigma_{\mathrm{gy}}^{2}+\mathrm{ry} \sigma_{\mathrm{g}}^{2}$ \\
\hline $\mathbf{G} \times \mathbf{Y}$ & $(\mathrm{y}-1)(\mathrm{g}-1)=4$ & S.S.gy & S.S.gy/(y-1) $(\mathrm{g}-1)$ & $\sigma_{\mathrm{e}}^{2}+\mathrm{r} \sigma_{\mathrm{gy}}^{2}$ \\
\hline Combined error & $\mathrm{y}(\mathrm{r}-1)(\mathrm{g}-1)=8$ & S.S.e/y & S.S.e $/ \mathrm{y} / \mathrm{y}(\mathrm{r}-1)(\mathrm{g}-1)$ & $\sigma_{\mathrm{e}}^{2}$ \\
\hline
\end{tabular}

$\sigma_{g}^{z}=\frac{M \cdot S \cdot g-\left(\sigma_{e}^{2}+r \sigma_{g y}^{2}\right)}{r y}$

$\sigma_{y}^{2}=\frac{M \cdot S \cdot y-\left(\sigma_{g}^{2}+r \sigma_{g y}^{2}\right)}{r g}$

$\sigma_{g y}^{2}=\frac{M \cdot S \cdot g y-\sigma_{e}^{2}}{r}$

$\sigma_{p h}^{2}=\sigma_{e}^{2}+\sigma_{g}^{2}+\sigma_{g y}^{2}$

Where; $\sigma_{g}^{2}, \sigma_{y}^{2}, \sigma_{g y}^{2}$ and $\sigma_{p h}^{2}$ types of variances of genotypes, years, genotypes $\times$ years interaction and phenotypes, respectively.

Heritability in broad sense was calculated as illustrated by Falconer (1989), using the following formula

$H_{b s}^{2}=\frac{\sigma_{g}^{2}}{\sigma_{p h}^{2}} \times 100$

Genotypic coefficient of variation (GVC) was estimated according to the procedure outlined by Burton (1952) as follows:

$G V C=\frac{\sqrt{\sigma_{g}^{2}}}{\bar{x}} \times 100$

Simple correlation coefficients ( $r$ ) were calculated for different pairs of the studied characters as shown by Dospekhove (1984)

\section{RESULTS AND DISCUSSION}

The results in Table (2) reflected wide differences among and within base populations of the three ecotypes of white radish for most of the studied characters. Concerning mean values, Balady Kafr ElSheikh had the longest foliage $(26.7 \mathrm{~cm})$, the most complete leaf shape, the least hairiness and the heaviest root (44.7 g). Meanwhile, Balady Sohag gave the highest number of leaves/plant.

Although, there were insignificant differences among the three ecotypes; with respect to means of foliage weight, root length and root diameter; there were wide differences in their ranges and coefficients of variation (C.V.\%), regarding the mentioned characters. The coefficients of variation values were higher than $25 \%$ for base populations of the three ecotypes in the most studied characters. 
The characters that showed variabilities higher than $25 \%$ were leaf shape (in Balady Alexandria and Balady Sohag), foliage weight (in Balady Kafr El-Sheikh), root length (in Balady Alexandria and Balady Kafr ElSheikh), hairiness (Balady Alexandria and Balady Sohag), root weight (in the three ecotypes), and shape index (in Balady Kafr El-Sheikh and Balady Sohag). The highest detected variability values that were also reflected by the noticed wide ranges for most of the studied characters, suggested the high potentialities of selection in the original populations of radish for improving such characters. Generally, it might be stated that all characters could be improved through mass selection method, but with varying degrees depending upon the amount of variation present in the population, the selection intensity and the heritability of the concerned characters.

Data in Table (3) illustrated that mass selection was effective on enhancing most of the characters of Balady Alexandria. However, the differences between cycle1 and cycle 2; regarding mean values of foliage length, No. leaves, foliage weight, and root diameter appeared insignificant. The second cycle of mass selection was noticed to be more effective on improving the mean values of root length, hairiness, and root weight. Meanwhile, mean value of leaf shape was not affected by mass selection, but its coefficient of variation decreased from $25 \%$ in base population to $6.6 \%$ in cycle 2. Furthermore, coefficients of variation for root length, hairiness, and root weight were reduced from $29.6 \%$, $29.1 \%$, and $29.6 \%$ in base population to $12.0 \%, 5.6 \%$, and $13.0 \%$ in cycle 2 of mass selection, respectively.

The data concerning the performances of Balady Kafr El-Sheikh characteristics; foliage length, No. leaves, leaf shape and root weight; illustrated that the mean values of these characters were noticed to be significantly increased after practicing the mass selection method for two cycles (Table, 4). Regarding foliage weight, only one cycle of mass selection was enough to enhance the mean value of this character. Meanwhile, mass selection method did not affect the other characters; i.e., root length, hairiness, root diameter, and shape index. On the other hand, mass selection method was effective in reducing coefficients of variation and the ranges of most of the studied characters, which became narrower than those of the base populations.

With respect to Balady Sohag, the obtained results in Table (5) illustrated that the second cycle of mass selection was more effective than the first one in enhancing mean values of foliage length, No. leaves, root length, root diameter, and root weight, though insignificant differences were detected between cycle1 and cycle 2 regarding mean values of leaf shape, foliage weight, hairiness, and root shape index. For a breeder, shape change itself might be an important target, because it affects the stability of the shape required for the constant supply of roots with an adequate shape, during the period around harvest time. Although several studies have been conducted on the morphological development of the roots of rooted vegetable crops (Rosenfeld ,1998; Soujala, 1999; Rosenfeld et al., 2002), a little attention was given to genetic variations in the changes in shape during growth. The estimated coefficients of variation (C.V.\%) and the ranges of all studied characters of the derived population after two cycles of mass selection were noticed to be lower and narrower, relative to those of the base populations.

Mean squares of the combined analysis for the studied traits of all studied radish genotypes were tabulated in Table (6). Mean squares of genotypes were found highly significant for only three characters; i.e., No. of leaves, leaf shape and hairiness. With regard to genotype $\times$ year component of variance, it did not reach the significant level in all studied traits. The insignificance of this component showed that the selected genotypes succeeded to posses the same good performances in the two years of the test. Mukhdoomi et al. (2007) evaluated twenty three genotypes of radish (Raphanus sativus L), and reported that the analysis of variance revealed highly significant differences among genotypes for all the traits.

The partitioning of variance into its various components in (Table, 7) revealed that a large portion of total variances of most studied traits, in all radish ecotypes, would be attributed to genotypes. It should be mentioned here that genetic variance would be biased upward since it contains non-partitioned genotypic $\times$ location source of variance (Comstock and Robinson, 1952); so, these results could be accepted under the designed conditions of this investigation and any wider implications warrant further research.

The estimated broad sense heritability of the various studied characters reflected high values $(>80 \%)$ in most studied traits of radish ecotypes (Table, 7).

These results gave information on the magnitude of genetic variation (Dully and Moll, 1969).

However, Herbert et al. (1955) pointed out that heritability alone gives no - indication of the amount of progress expected from selection. However, it seems to be most meaningful when accompanied by the estimates of genetic coefficient of variability (Burton, 1952). On the other hand, Herbert et al (1955) stated that heritability estimates, when related to the expected 


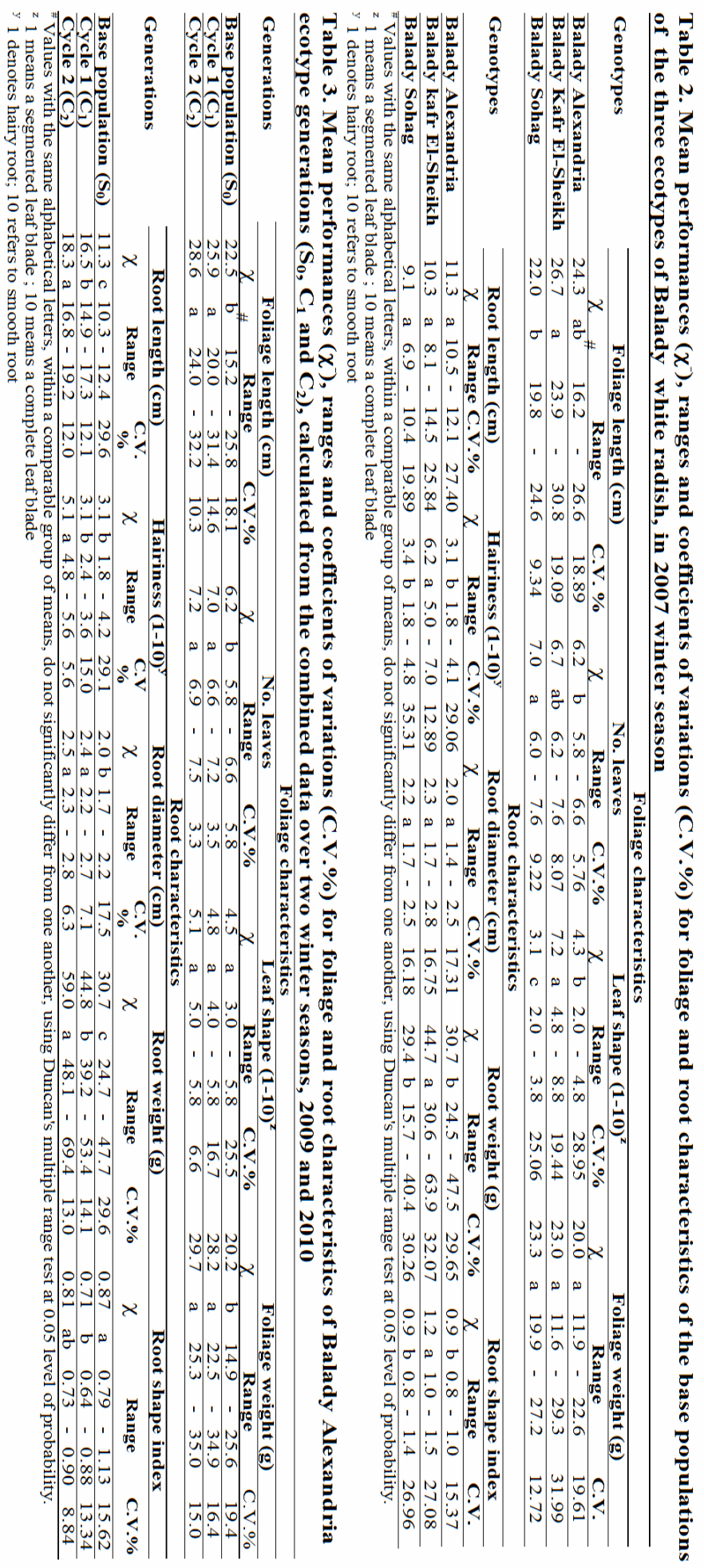




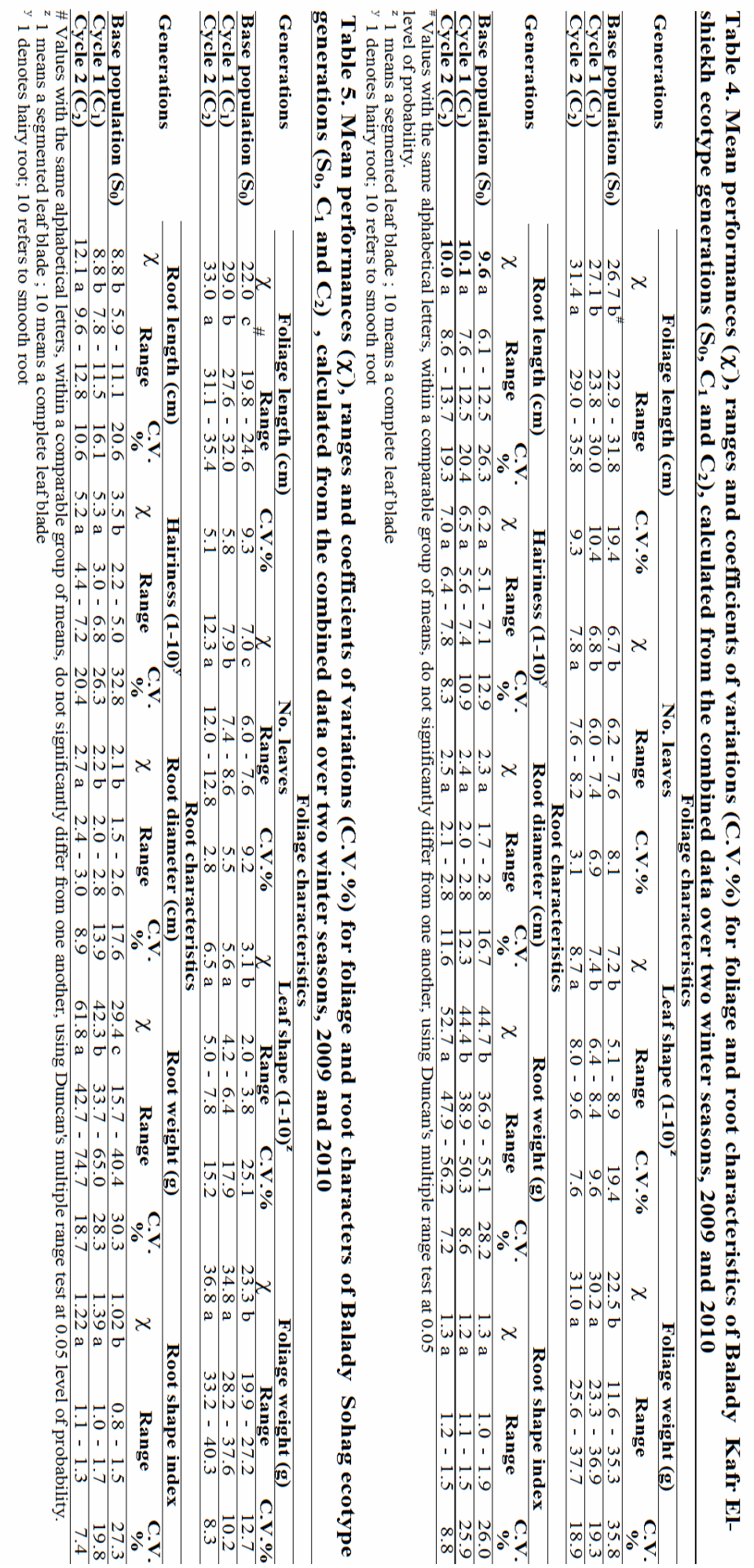




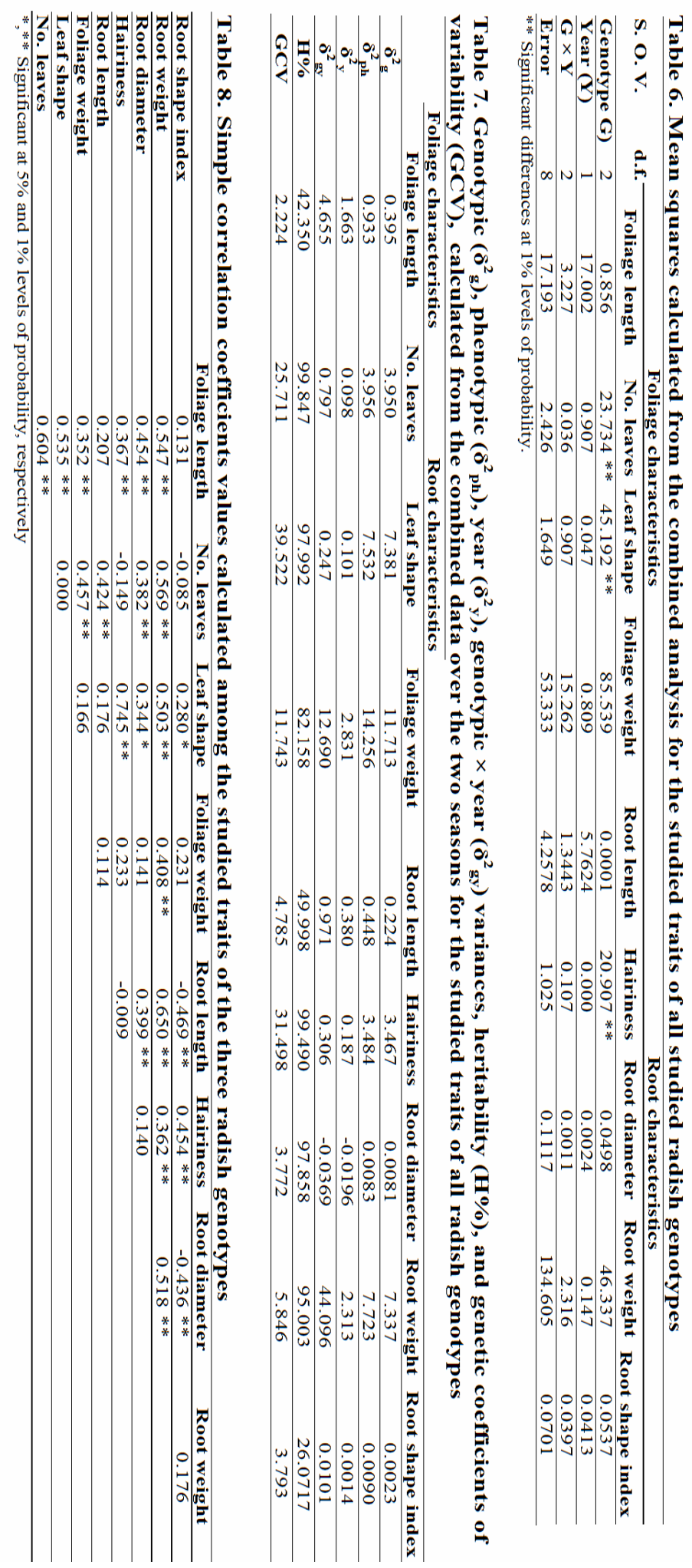


genetic advance, a considerable progress in modifying some characters by selection could be expected. Depending on these points of view, when the relatively high or moderate estimates of heritability related to relatively high or moderate estimates of genetic coefficient of variability, it would resulted in noticeable gain from selection. Therefore, No. of leaves, leaf shape, and hairiness might be improved by selecting the top $5 \%$ of the studied genotypes of radish.

Table (8) shows the estimated values of correlation coefficients among the studied traits of the three radish genotypes. Foliage length was positively correlated with all studied characters, except root shape index and root length. Furthermore, root weight was positively correlated with all studied characters, except root shape index. Meanwhile, foliage weight was positively correlated with foliage length, No. leaves, and root weight. Mapari et al. (2010) reported that root yield per plant was closely associated with number of leaves per plant at harvest, fresh weight of leaves, root length and total plant weight.

\section{REFERENCES}

Burton, G.W. 1952. Quantitative inheritance in grass. Proceeding of the 6 international grassland congress. Pennsylvania, U.S.A. : 217-283.

Comstock, R.E. and H.F. Robinson 1952. Genetic parameters, their estimation and significance. Proc. 6th Inter. grassland cong. 1: 284-291.

Dospekhov, P.A. 1984. Field experimentations. Statistical Procedurs, Mir bublifhebro Moscow, pp. 349.
Dully, J.W. and R.H. Moll. 1969. Interpretation and use of estimates of heritability and genetic variance in plant breeding. Crop Sci. 9: 257-262.

Falconer, D.S. 1989. Introduction to quantitative genetics. third edition, Longman, New York, U.S.A.

Herbert, W.J.; H.F. Robinson and R.E. Comstock. 1955. Estimates of genetic and environmental variability in soybeans. Agron. J. 47: 314-318.

Mapari, A.V.; P.D. Peshattiwar; V.N. Dod and A. Thorat. 2010. Correlation and path analysis studies in radish. The Asian Journal of Horticulture. 4 (2): 285-288.

Mukhdoomi, M.I.; G. Din; N. Ahmed; K. Hussain and N. Gazala. 2007. Genetic variability and selection parameters for yield attributes in radish (Raphanus sativus L.). The Asian Journal of Horticulture. 2(2):141-143.

Rosenfeld, H.J. 1998. Maturity and development of the carrot root (Daucus carota L.). Gartenhauwissenschafl. 63: 8794.

Rosenfeld,H.J.; K.S.Dalen and K.Haffner 2002. The growth and development of carrot roots. Gartenbauwissenschaft. 67: $11-16$.

Schultheis, J. R. 1993. Leaflet No.25 on radish. North Carolina State University. (C.F. World Wide Web).

Soujala,T. 1999. Cessation of storage root growth of carrot in autumn. J. Hortic. Sci. Biotechnol. 74: 475-483.

Thompson, R. 1969. Some factors affecting carrot root shape and size. Euphytica 18:277-285

Wahba R.M.; W.S. Ragheb and W.M. Rizk. 1998. Breeding studies on white radish (Raphanus sativus L). Adv. Agric. Res. 3(2): 301-307. 


\section{إلمص لمص

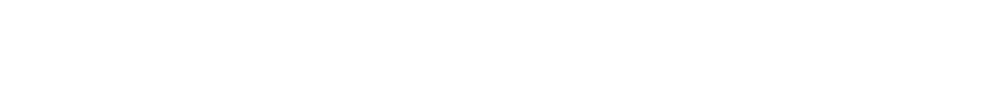

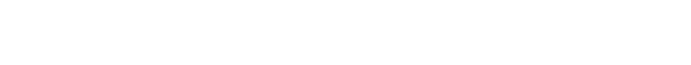

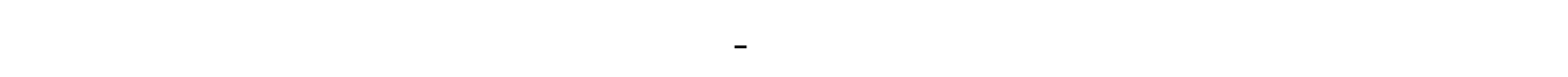

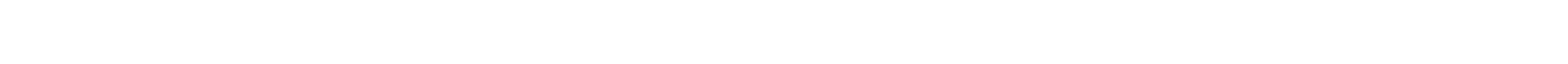

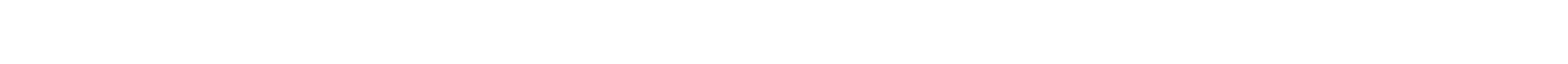

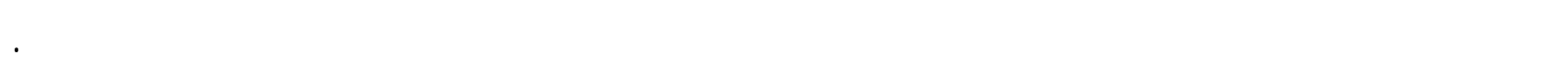

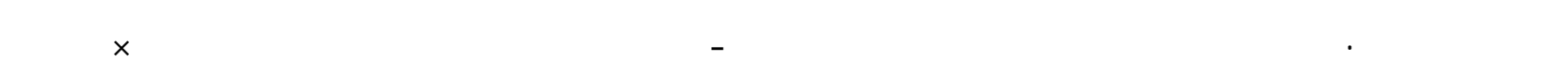

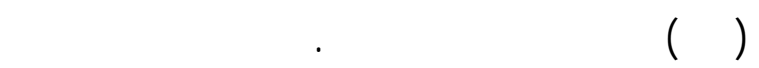

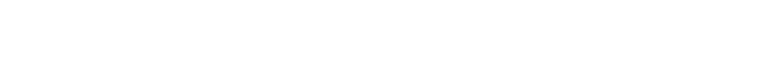

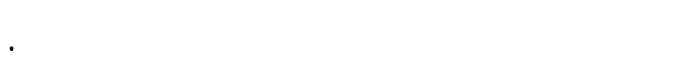
اللهستخلهة من الفبل البلدى.

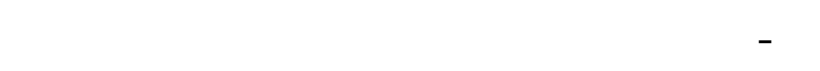

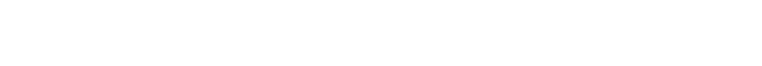

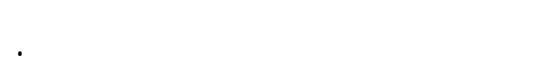

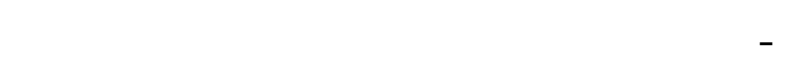

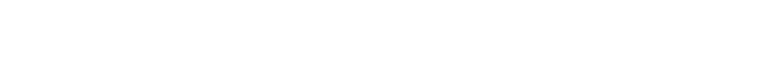
منطول العش وكدد الأورق/ النبت ووزن الحزر.

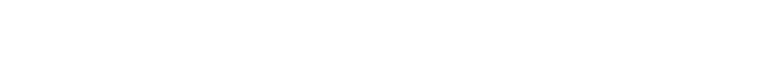

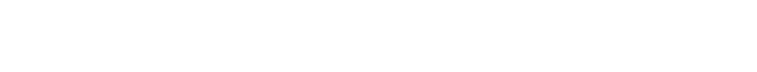

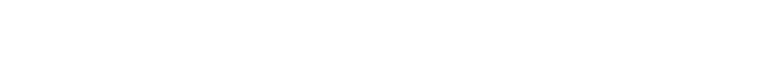

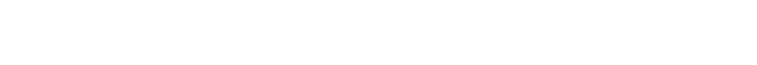
بأفسهم: بدون انتاع الطرق العلمة. ولكن تلخيص أهم التنائج فيما يلي:

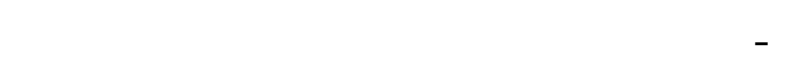

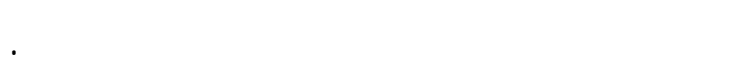

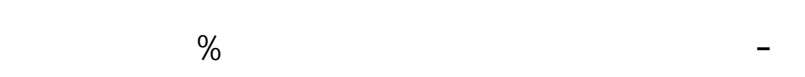

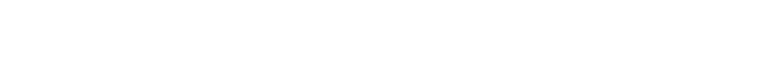
الصفلت إلمروية.

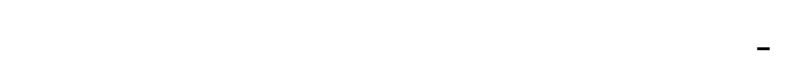

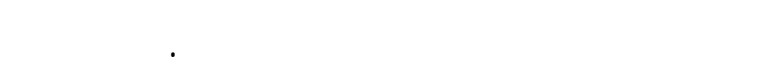

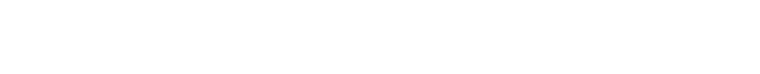
الصفلت إلمروسة أضنق.

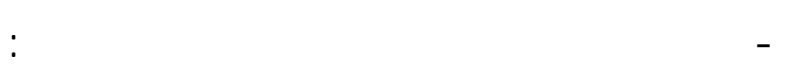
عدد الأورق/ النبت وشكل الورقة وكنالة الثعتلت 